\title{
A Mechanism for Biological Control-Tempo-Spatial Synchronization of Natural Enemy and Insect Pest Population Dynamics at the Peak by Increase of Biodiversity
}

\author{
Long Zhang and Xiangyong Li \\ Department of Entomology, China Agricultural University, Beijing 100193, China
}

\begin{abstract}
To reveal the mechanism of control of the Woolly Apple Aphid (Eriosoma lanigerum Hausm, WAA) by increase of biodiversity in the apple orchard, a consecutive two-year field trials were conducted in Yunnan province, China. The results showed that the peak of natural enemy density curve in the cover cropping orchard was well temporally synchronized with that of the WAA density on trees, but did not synchronize with that of WAA density on trees in clean orchard. In addition, the frequency of natural enemies and WAA within a same sample in cover cropping orchard was obviously higher than that in clean cultivated orchard during the peak of population curves, indicating that natural enemies spatially synchronized with aphids. The density of WAA for the whole growing season in cover cropping orchard was much less than that in clean orchard. Therefore, the temporal-spatial synchrony of natural enemy and aphid populations was proposed as one of the mechanisms for aphid control in cover cropped orchards.
\end{abstract}

Key words: Synchrony, natural enemies, aphid, Eriosoma lanigerum, cover crops, apple orchard, biological control, temporal-spatial dynamics.

\section{Introduction}

Ecosystems with higher diversity are more stable with higher resistance to pest invasion, or an ability to avoid or withstand disturbance, and recover following disturbance [1-3]. Many studies indicated that the weeds and covering crops present in agroecosystems not only increase plant biodiversity, but also offer many important requisites for natural enemies, such as alternative prey/hosts, pollen or nectar as well as microhabitats [4-9].

Several hypothesis have been proposed to explain insect pests controlled by the increase of biodiversity [3]. However, few hypotheses are from population dynamics view but from nutrition or behaviour aspects. Some mentioned on the effects of temporal synchrony of natural enemies [10-13]. But those were not

Corresponding author: Long Zhang, Ph.D., research fields: ecology and pest management. particularly detailed experimental studies.

Here the paper reports on a consecutive two-year study on the effects of cover crops on relationships between natural enemy and woolly apple aphid populations in apple orchards. The results indicated that temporal-special synchronization of natural enemies and pest insects is a mechanism for pests control in cover cropped orchards.

\section{Material and Methods}

\subsection{Studied Site}

The study was conducted in the apple orchards at Zhaotong city of Yunnnan province, China (27 $14^{\prime} 40^{\prime \prime}$ N, 103 $38^{\prime} 19^{\prime \prime}$ E). The orchards consisted of Red Fuji apples, planted in 1995, $3 \mathrm{~m}$ apart within rows and 5 $\mathrm{m}$ between rows. The orchards were divided into two separate blocks by a road, one treated with cover crop, about 4 ha, and the other remained clean cultivated, about 1.3 ha. 


\section{A Mechanism for Biological Control-Tempo-Spatial Synchronization of Natural Enemy and Insect Pest 539 Population Dynamics at the Peak by Increase of Biodiversity}

In the cover cropped apple orchard, ryegrass (Lolium perenne), clover (Trifolium repens) and alfalfa (Medicago sativa) were planted in July, 2002 as cover crops at a ratio of $50 \%, 33 \%$ and $17 \%$ respectively. The cover crops were mowed four or six times per year keeping their height at about $10-35 \mathrm{~cm}$. No insecticide was sprayed on the crops. On 14th of June (year), in the clean cultivated apple orchard, groundcover was mown between rows.

\subsection{Sampling Methods}

Twenty-five apple trees in the center of each orchard block were investigated on each time. The branches were marked with red color, at four directions (east, south, west and north) of each sampled tree. Sampling was conducted weekly from March to October of 2004 and 2005. All active arboreal colonies of WAA and individuals of natural enemies on the marked branches in both blocks were counted. On the ground, between the trees sampled row, sweep net was used to collect the insects in the cover crops. Swept with 20 sweeps at each sampling site. The collected insects were identified in the laboratory.

\subsection{Analysis Methods}

Data were grouped in two groups of arthropods for analysis: woolly apple aphid and natural enemies, and analyzed by t-test. Linear correlations between the densities of woolly apple aphid and natural enemies in tree, densities of natural enemies in tree and in crop were calculated by regression analysis with the SPSS12.0 software (SPSS INC. Chicago, USA).

\section{Results}

\subsection{Control of WAA by Cover Cropping in Apple Orchard}

In 2004, the WAA population density after the first peak on the $3 \mathrm{rd}$ of June, at 0.75 colonies/shoot, reached another peak on 18th of August, at 0.48 colonies/shoot, then remained at a lower level in the clean cultivated orchard (Fig. 1a). The outbreak period of WAA lasted about 6 months. In contrast, in the cover cropped orchard, the WAA population density peaked on 3 June, at 0.62 colonies/shoot, and remained at a very low level lasting for 3 months, without the need for any control action (Fig. 1b),.

In 2005, the WAA population densities were much higher in the clean cultivated apple orchard than in the cover cropped orchard. The density of the first peak of WAA in the clean cultivated orchard was 10 colonies/shoot, and the second one was about 14.9 colonies/shoot. In contrast, the first peak of WAA in the cover cropped orchard was 0.75 colonies/shoot, and the second about 1.76 colonies/shoot (Figs. 2a and 2b). Therefore, WAA populations in the cover cropped apple orchard were effectively suppressed.

\subsection{Synchrony of Natural Enemy and Woolly Apple Aphid Occurrence in the Cover Crop Orchard}

In 2004, there were two peaks of WAA population dynamics during the season till the late of August in the clean cultivated orchard, with the natural enemies oscillating dramatically in three peaks (Fig. 1). The composite population of natural enemies included Coccinella septempunctata Linnaeus, Hippodamia variegata Goeze, Leix axyridis Pallas, Propylea japonica Thunberg, Chrysopa sinica Tjeder, Sphaerophoria Indiana, Meranostoma mellium, Parasyrphus tarsatus Zetterstedt and Aphelinus mali Hald (Table 1). During these peaks, the first peak in the early of the season was resulted from the migration of natural enemies from outside of the orchard, while the other two peaks of natural enemies followed the WAA population peaks with a delay of about 20 days. The natural enemy occurrences were not in synchrony with the WAA (Fig. 1a). In contrast, there was only one peak of WAA, and following this peak, the population density was maintained at low levels for 3 months in the cover cropped orchard. It is worth to note that the natural enemy population was very well synchronized with the WAA population, and 


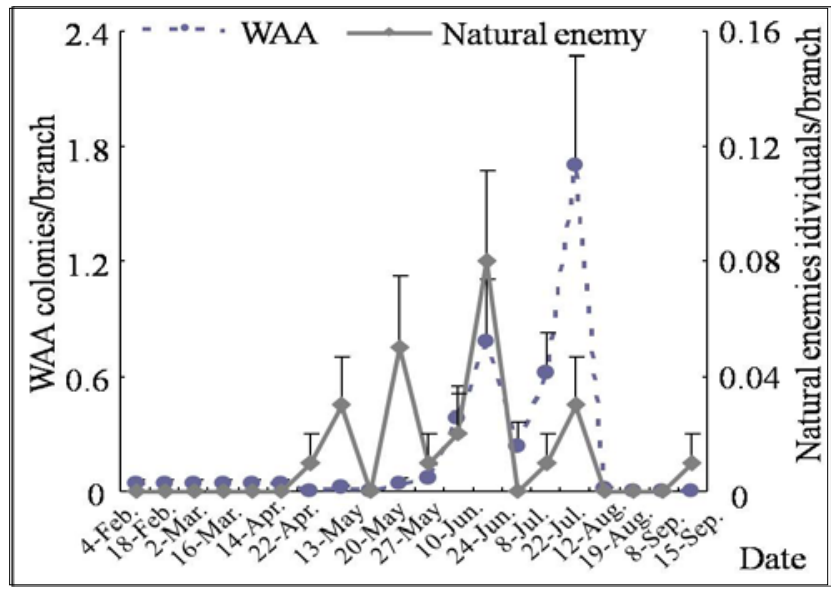

(a)

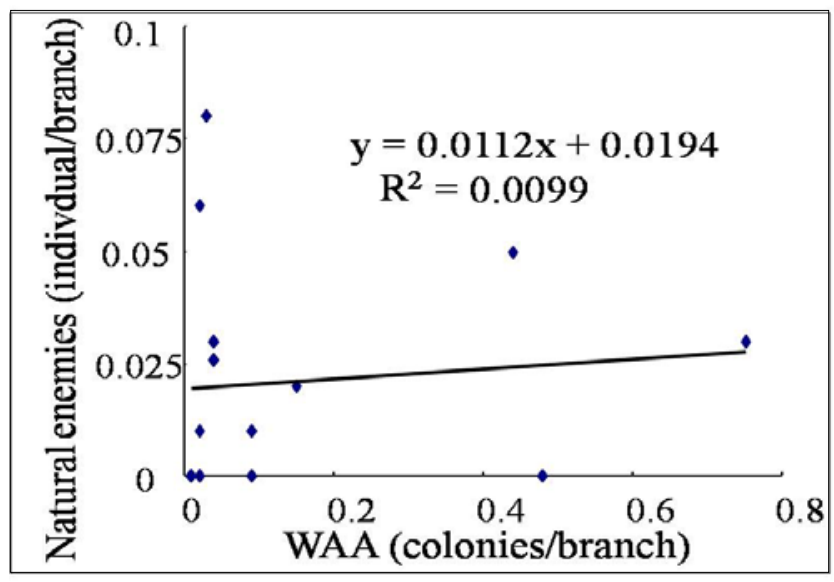

(c)

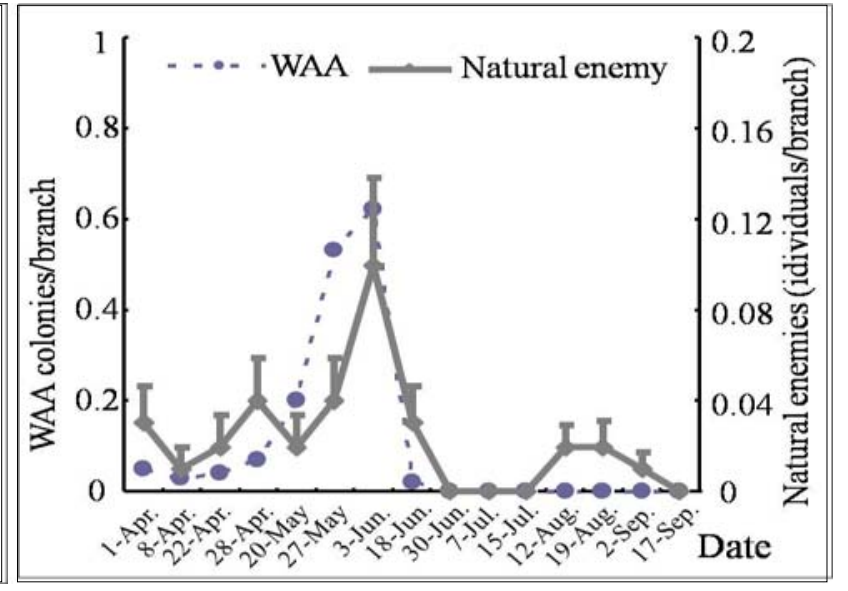

(b)

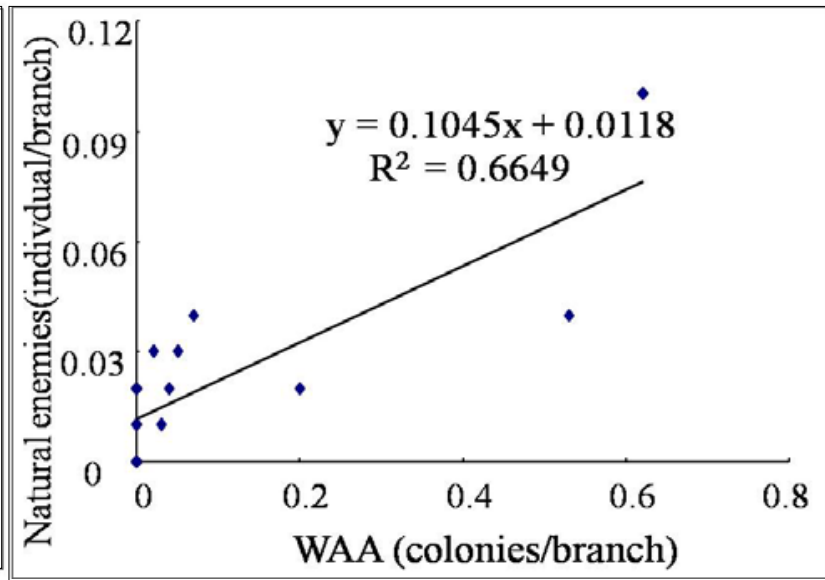

(d)

Fig. 1 The dynamics of woolly apple aphid and natural enemy populations on trees in the clean cultivated (a), and those in cover crops orchards (b), the regression analysis of the relationships between the densities of woolly apple aphid colonies and natural enemies on trees in the clean cultivated (c) $\left(R^{2}=0.0099, P>0.05\right)$, and those in cover crops orchards (d) $(2004) R^{2}=$ 0.6649, $\mathrm{P}<0.01$ ), error bars denote significant difference at the $5 \%$ level, least square means test.

the natural enemy populations were quite stable following the peak (Fig. 1b). The regression analysis of the density of WAA to that of natural enemies in the trees showed that in the clean cultivated orchard, there was hardly any relation between densities of WAA and that of natural enemies (Fig. $1 \mathrm{c}, \mathrm{R}^{2}=$ $0.0099, \mathrm{P}>0.05$ ). In contrast, there was a positive relation in the cover crops orchard (Fig. $1 \mathrm{~d}, \mathrm{R}^{2}=$ 0.6649, $\mathrm{P}<0.01)$.

The peaks of natural enemy and woolly apple aphid populations in the clean cultivated orchard were not synchronous (Fig. 2a). In contrast, in the cover cropped orchards, the peaks of these two insect populations were highly synchronous in 2005 (Fig.
$2 b)$. The regression analysis of the WAA density to that of the natural enemies in the trees showed that in the clean cultivated orchard, there was a lesser relationship between densities of WAA and that of natural enemies (Fig. 2c, $\mathrm{R}^{2}=0.1815, \mathrm{P}>0.05$ ). However, there was a higher positive relation in cover cropped orchard (Fig. 2d, $\mathrm{R}^{2}=0.2315, \mathrm{P}<0.01$ ).

Besides, when the spatial relationships between natural enemies and insect pests in cover cropped orchards, represented by the frequency of natural enemies and insect pests in same sample were examined. The results showed that during the peak period of population curve, mid of June, 2004, the frequency of natural enemies and insect pests within 


\section{A Mechanism for Biological Control-Tempo-Spatial Synchronization of Natural Enemy and Insect Pest 541 Population Dynamics at the Peak by Increase of Biodiversity}

the same sample formed an obvious peak and was much higher in cover cropped orchard, but no obvious peak and lower frequency in clean cultivated orchard (Fig. 3). Besides, during early of season March to May of 2004, the frequency of natural enemies and pests in same sample were higher in cover cropped orchard, by contrast with clean cultivated orchard which is nearly zero (Fig. 3 ).

\subsection{Relationship between Natural Enemies in Tree and Cover Crops}

In order to find the relationship of natural enemies on cover crops and trees, the analysis of the data which represented by density of natural enemies on tree and ground (or cover crops) in the two consecutive years was conducted. In 2004, in the clean cultivated orchard, the first peak of natural enemies on trees was synchronous with the first peak of that on ground, but the following peaks of both were never synchronous (Fig. 4a). The density of natural enemies on trees had three smaller peaks, however, these were synchronized with that on crops in the cover cropped orchard (Fig. 4b). In the clean cultivated orchard, the natural enemy density on trees had no clear relationship

Table 1 The species of natural enemies in cover cropped or cleaned orchard.

\begin{tabular}{|c|c|c|c|}
\hline & Natrual enemies & Cover cropped & Cleaned \\
\hline \multirow{4}{*}{ Coccinellidae } & *Leis axyridis (Pallas) & + & + \\
\hline & *Coccinella septempunctata Linnaeus & + & + \\
\hline & *Hippodamia variegata (Goeze) & + & - \\
\hline & *Propylaea japonica (Thungerg) & + & + \\
\hline \multirow{3}{*}{ Anthocoridae } & Orius bifilarus & + & - \\
\hline & Orius minutus & + & + \\
\hline & Orius similis & + & - \\
\hline Chalalcididae & *Aphelius mali & + & + \\
\hline Aaphidiidae & Diaeretilla rapae M lntosh & + & + \\
\hline \multirow{8}{*}{ Ichneumqnidae } & Ahhanistes sp. & + & + \\
\hline & Heresiarehes sp. & + & + \\
\hline & Triclistus sp. & + & - \\
\hline & Dichelobosmina sp. & + & - \\
\hline & Promethes sp. & + & - \\
\hline & Agypon sp. & + & - \\
\hline & Heresiarches sp. & + & - \\
\hline & Xanthoeampopiex sp. & + & - \\
\hline Proctotrupidae & Proctotrupidae sp. & + & + \\
\hline \multirow{3}{*}{ Coenagrionidae } & Coenagrion convalescens Bertenef & + & + \\
\hline & Coenagrion calamorum Ris & + & + \\
\hline & Coenagrion sp. & + & + \\
\hline Chrysopidae & *Chrysopa sinica Tjeder & + & - \\
\hline \multirow{4}{*}{ Syrphidae } & *Sphaerophora indiana & + & + \\
\hline & *Meranostoma mellium & + & + \\
\hline & *Parasyrphus tarsatus & + & - \\
\hline & *Syrphus balteatus & + & + \\
\hline Forficulidae & *Euborellia pallipes Shiraki & + & + \\
\hline
\end{tabular}

* “+”-present, "—”- -absent and "*”- the natural enemies for woolly apple aphid. 
542 A Mechanism for Biological Control-Tempo-Spatial Synchronization of Natural Enemy and Insect Pest Population Dynamics at the Peak by Increase of Biodiversity

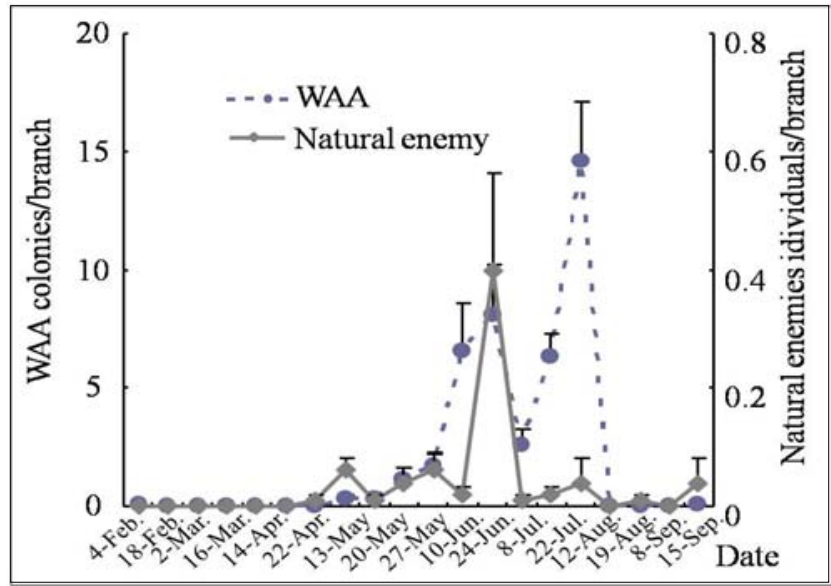

(a)

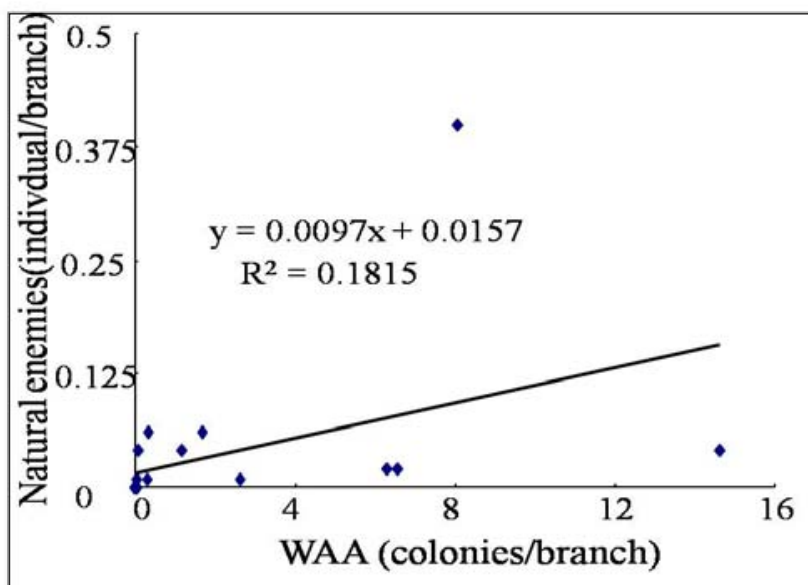

(c)

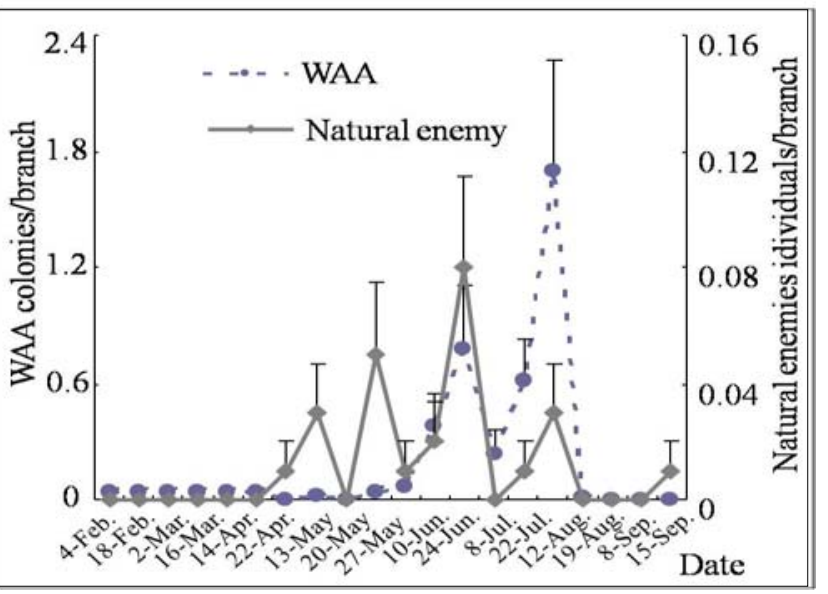

(b)

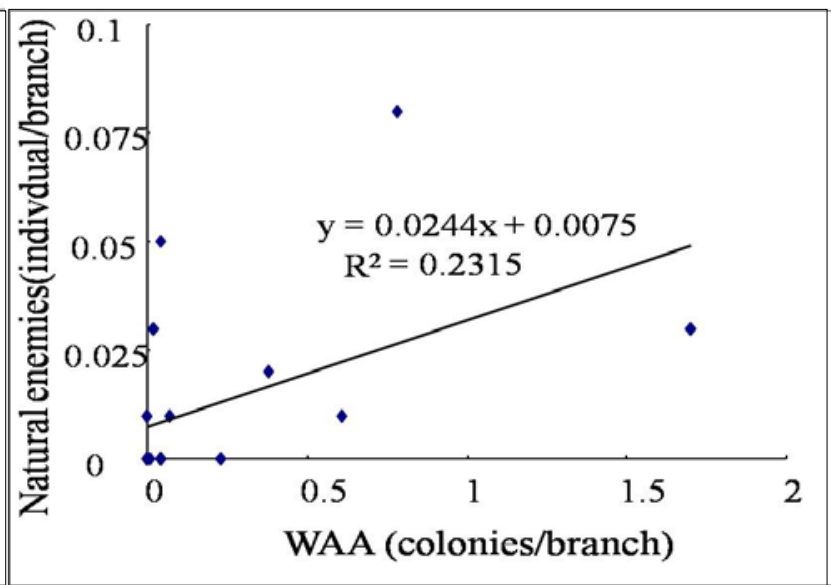

(d)

Fig. 2 The dynamics of woolly apple aphid population and natural enemy populations on trees in the clean cultivated (a), and those in cover crops orchards (b), the regression analysis of the relationships between the densities of woolly apple aphid colonies and natural enemies on trees in the clean cultivated (c), and those in cover crops orchards (d) (2005), (error bars denote significant difference at the $5 \%$ level, least square means test).
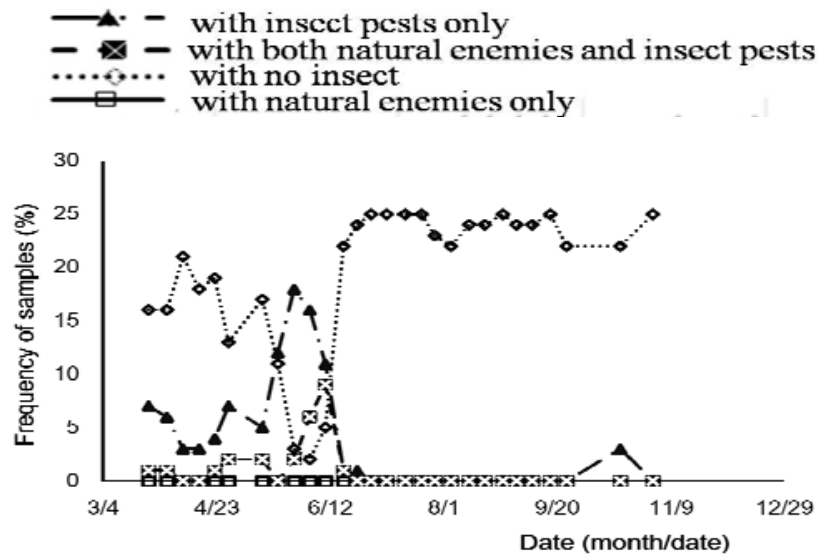

(a)
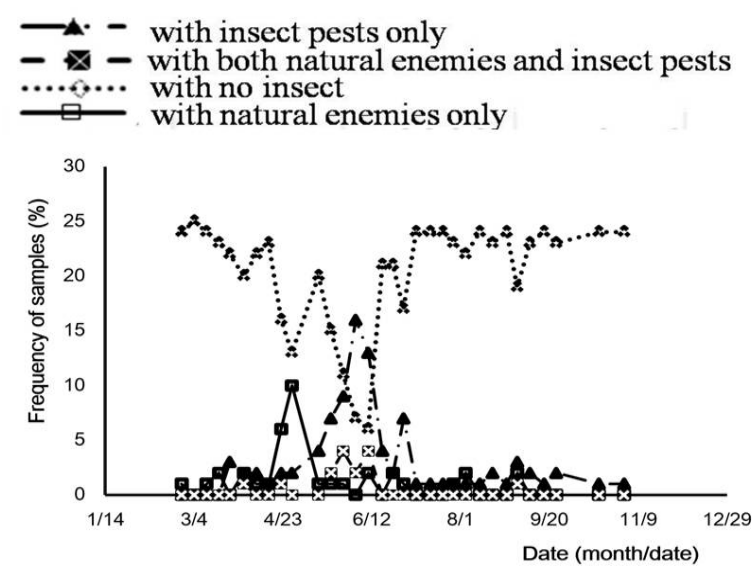

(b)

Fig 3 The frequency of natural enemies and insect pests within the same sample in cover cropped (a) and clean cultivated orchards (b) in 2004. 


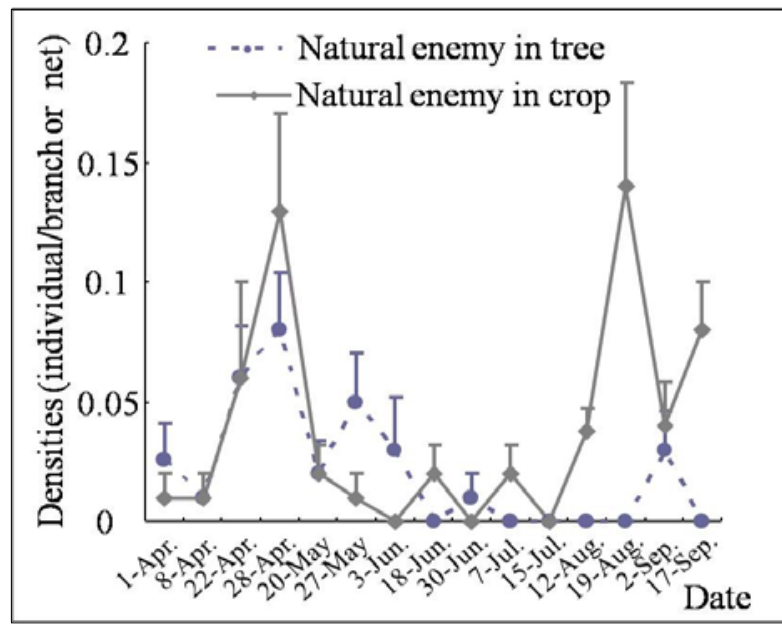

(a)

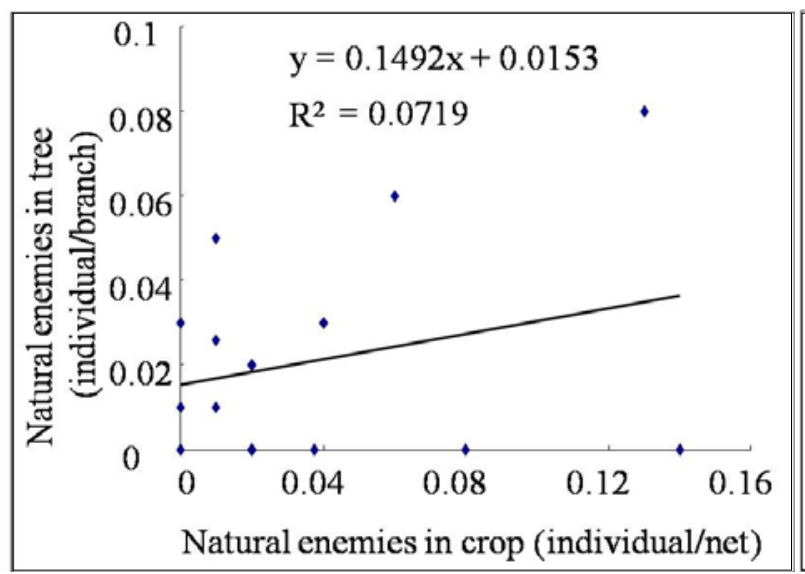

(c)

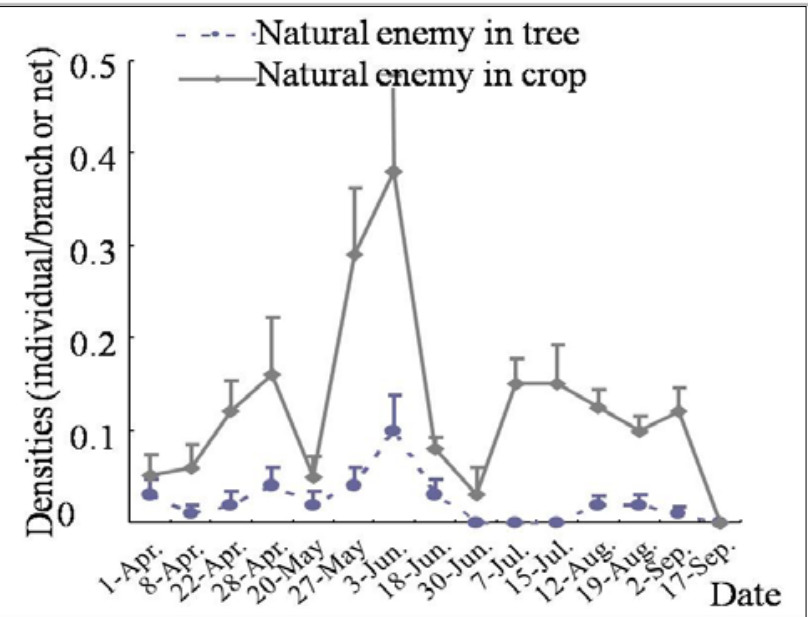

(b)

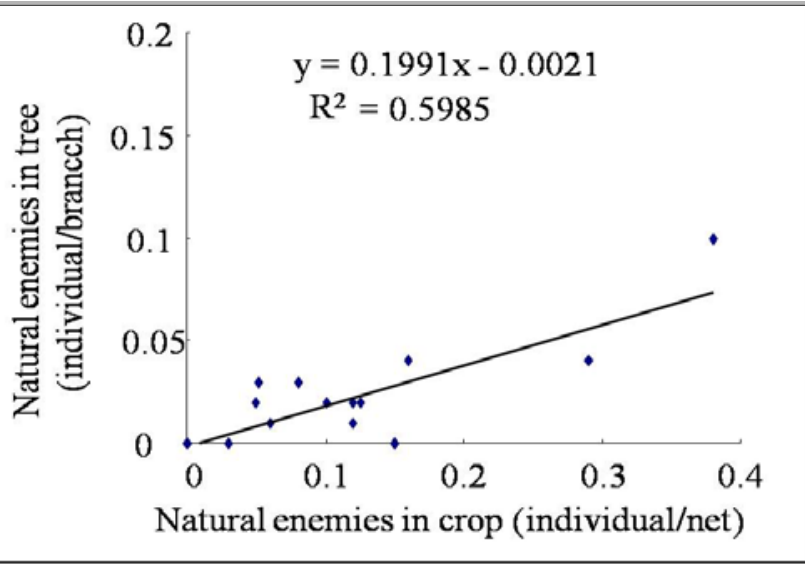

(d)

Fig. 4 The dynamics of natural enemies on trees and on the crop in the clean cultivated (a), and those in the cover crops orchards (b), the regression analysis of the relationships between the densities of natural enemies on trees and on the crops in the clean cultivated (c), or those in cover crops orchards (d) (2004).

with those on the ground (Fig. $4 \mathrm{c}, \mathrm{R}^{2}=0.0719, \mathrm{P}>$ 0.05). However, in the cover cropped orchard, natural enemy density on trees depended on the natural enemies on the crops (Fig. 4d, $\mathrm{R}^{2}=0.5985, \mathrm{P}<0.01$ ). In 2005, there was no positive relationship of natural enemy on trees and on the ground in the clean cultivated orchard $\left(\mathrm{R}^{2}=0.0017, \mathrm{P}>0.05\right)$ (Figs. 5a and $5 \mathrm{c}$ ). In contrast, in the cover cropped orchard, there was a greater positive relationship between the natural enemy on trees and on cover crops $\left(\mathrm{R}^{2}=\right.$ $0.2166, \mathrm{P}<0.01$ ) (Figs. 5b and 5d).

\section{Discussion}

Control of the WAA in the clean cultivated orchard required multiple applications of chemical pesticides and the pest still lasted until the end of the season in China. This paper's experiments showed that planting cover crops could effectively reduce the density of WAA. This result agrees with some reports on use of cover crops to control spider mites in orchards, leafhoppers in vineyards, leafhoppers and rosy apple aphids in apple orchards, caterpillars and codling moth in apple orchards, aphids in apple orchards and citrus red mite in citrus orchards [9, 14-21]. Apparently, the cover cropping plays an important role in augmentation and conservation of natural enemies.

The first peaks of natural enemy populations both in cover cropped and clean cultivated orchards might be the result of natural enemy migration from outside of the orchard. The peaks of natural enemy populations 


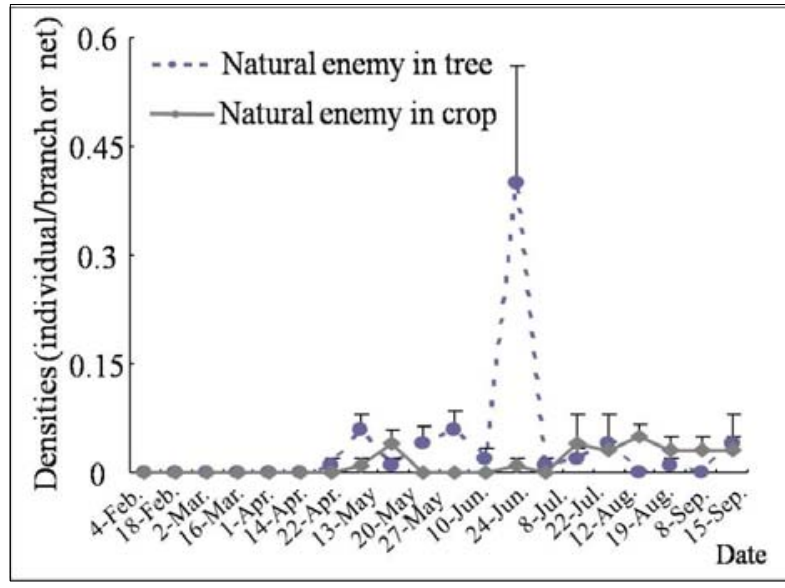

(a)

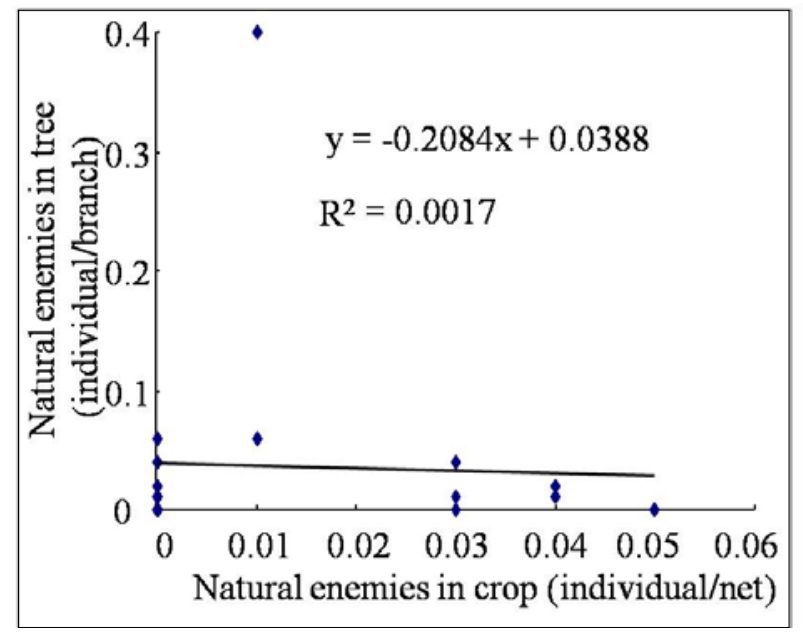

(c)

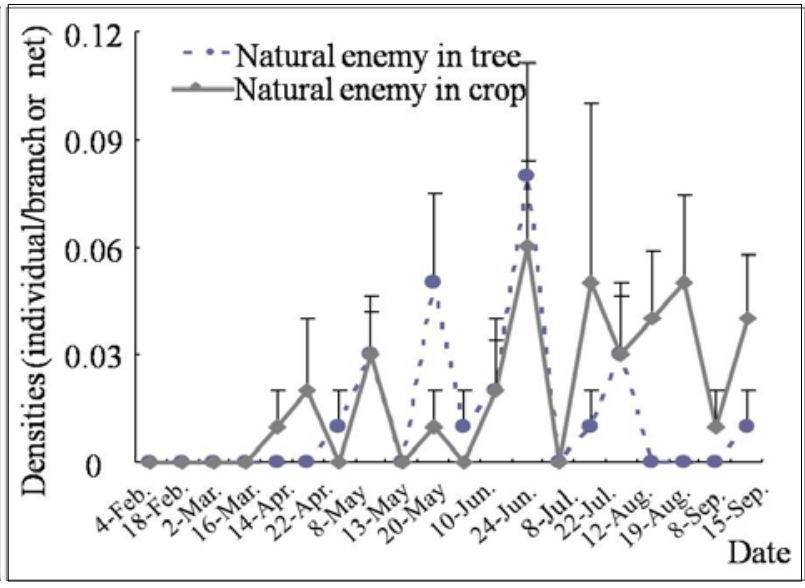

(b)

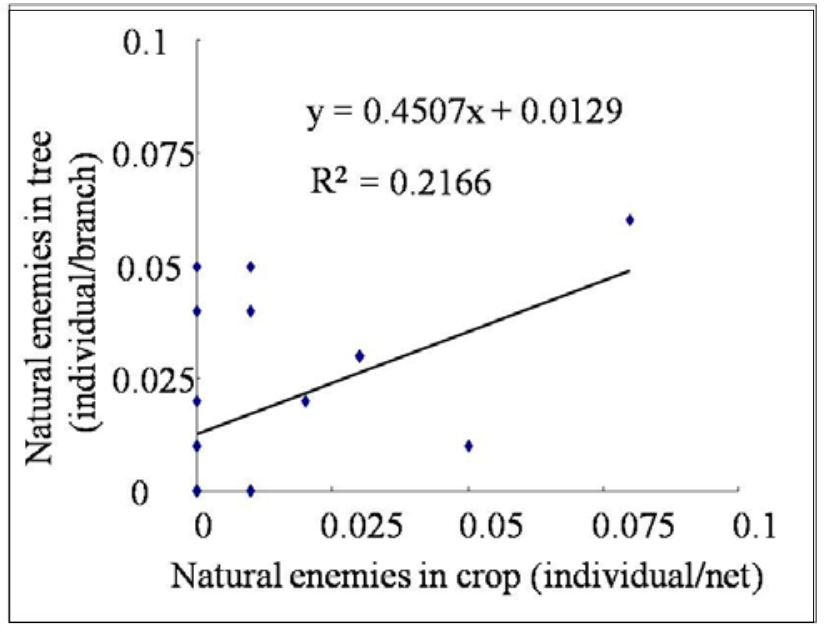

(d)

Fig. 5 The dynamics of natural enemies on trees and on the crops in the clean cultivated (a), and those in cover crops orchards (b), the regression analysis of the relationships between the densities of natural enemies on trees and on the crop in the clean cultivated (c), and those in cover crops orchards (d) (2005).

in the cover cropped orchard were greater, and occurred sooner and were well synchronized with the peaks of WAA. In contrast, peaks of natural enemies occurred at smaller levels and were delayed by two weeks after the peak WAA in the clean cultivated orchard.

The data suggests that the natural enemies on the trees originated partially from the cover crops, since the density of natural enemies in the trees occurred coincidently with that on the crops. Furthermore, the densities of natural enemies on the trees and cover vegetation in the cover crops orchard were higher than those in the clean cultivated orchard. The previous results showed that the numbers of generalized predators increased significantly during 2004-2005 growing seasons [22]. It was speculated that the diverse habitats offered many important requisites for adult predators and parasitoids, such as alternative prey and hosts in the cover crops orchard, which were not available in the clean cultivated orchard. Because early in the season, there were no blooms in the cover crops therefore, not providing nectar and pollen for the natural enemies, as mentioned by Risch, S. J. [2].

Several hypotheses have been developed to explain the control of insect pests in agroecosystems with increased plant diversity [3, 11, 23]. These hypotheses suggest that the numbers of natural enemies increase because the diverse plants provide predator and 


\section{A Mechanism for Biological Control-Tempo-Spatial Synchronization of Natural Enemy and Insect Pest 545 Population Dynamics at the Peak by Increase of Biodiversity}

parasitoids food or habitats but, few considered the importance of the synchronization of natural enemies in time and space with insect pests. The results demonstrated that increased canopy structure of plant and composition of plant species resulted in the synchrony of pests and natural enemies. Therefore, the tempo-spatial synchrony of natural enemies and insect pests should be treated as a new rule for biological control of insect pests by increase of plant diversity in agroecosystems.

In fact, synchronization is a general phenomenon and is considered important in nature because it explains interactions between population dynamics and extrinsic environmental variation, or predation [24]. Even though the mechanisms of spatio-temporal synchrony between populations are not very clear, it has been suggested that the synchrony may be caused by weather and dispersal, or predation, or both [25-29], which should be further studied.

\section{Acknowledgements}

Thank Dr. Mark Goettle to have made comment and revised for this manuscript. This work was supported by a grant from the Ministry of Agriculture of China. It is grateful to Mr. Xinsheng Gong, Gaohui Zhao and Ms. Xueqing Zhao for helping in this investigation.

\section{References}

[1] Pimentel, D. 1961. "Spices Diversity and Insect Population Outbreaks." Ann. Entomol. Soc. Am. 54: 76-86.

[2] Risch, S. J. 1983. "Intercropping as a Cultural Pest Control: Prospects and Limitations." Environ. Entomol. 12 (3): 625-629.

[3] Altieri, M. A., and Nicholls, C. L. 2004. Biodiversity and Pest Management in Agroecosystems. Second Edition, New York: Food Products Press.

[4] Van Emden, H. F. 1965. "The Role of Uncultivated Land in the Biology of Crop Pests and Beneficial Insects." Hortic. Sci. 17: 121-136.

[5] Altieri, M. A., and Wihtcomb, W. H. 1979. "The Potential Use of Weeds in the Manipulation of Beneficial Insects." Hortic. Sci. 14: 12-18.

[6] Wyss, E. 1995. "The Effects of Weed Strips on Aphids and Aphidophagous Predators in an Apple Orchard." Entomol. Exp. Appl. 75: 43-49.

[7] Brown, M. W., Van Der Zwet, T., and Glenn, D. W. 1997. "Impact of Ground Cover Plants on Pest Management in West Virginia, USA, Apple Orchards." Hortic. Sci. 24: 39-44.

[8] Smith, M. W., Arnold, D. C., and Eikenbary, R. D. 1996. "Influence of Groundcover on Beneficial Arthropods in Pecan.” Biological Control 6: 164-176.

[9] Yan, Y. H., Yu, Y., Du, X. G., and Zhao, B. G. 1997. "Conservation and Augmentation of Natural Enemies in Pest Management of Chinese Apple Orchards." Agric. Ecosyst. Environ. 62: 253-260.

[10] Letourneau, D. K., and Altieri, M. A. 1983. "Abundance Patterns of a Predator Orius tristicolor (Hemiptera: Anthoconidae) and Its Prey, Frankliniella occidentalis (Thysanoptera: Thripidae): Habitat Attraction in Polycultures Versus Monocultures." Environmental Entomology 122: 1464-1469.

[11] Letourneau, D. K. 1987. "The Enemies Hypothesis: Tritrophic Interaction and Vegetational Diversity in Tropical Agroecosystems.” Ecology 68: 1616-1622.

[12] Doutt, R. L., and Nakata, J. 1973. "The Rubus Leafhopper and Its Egg Parasitoid: An Endemic Biotic System Useful in Grape-Pest Management." Environmental Entomology 2: 381-386.

[13] Flaherty, D. 1969. "Ecosystem Trophic Complexity and the Willamette Mite, Eotetranychus willamettei (Acarine: Tetranychidae) Densities." Ecology 50: 911-916.

[14] Settle, W. H., Wilson, L. T., Flaherty, D. L., and English, G. M. 1986. "The Variegated Leafhopper, as Increasing Pest of Grapes." Calif. Agric. 40: 30-32.

[15] Hanna, R., Zalom, F. G., and Elmore, C. L. 1996. "Integrating Cover Crops into Vineyards." Grape Grower 30 (4): 18-36.

[16] Daane, K. M., Costello, M. J., Yokota, G. Y., and Bentley, W. J. 1998. "Can We Manipulate Leafhopper Densities with Management Practices?" Grape Grower 16 (3): 26-43.

[17] Altieri, M. A., and Schmidt, L. L. 1986. "Cover Crops Affect Insect and Spider Populations in Apple Orchards." Calif. Agric. 40: 15-17.

[18] Leius, K. 1967. "Influence of Wild Flowers on Parasitism of Tent Caterpillar and Codling Moth.” Can. Entomol. 99: 444-446.

[19] Zandstra, B. H., and Motooka, P. S. 1978. "Beneficial Effects of Weeds in Pest Management: A Review." PANS 24: 333-338.

[20] Wyss, E., Niggli, U., and Nentwig, W. 1995. "The Impact of Spider on Aphid Populations in Strip-Managed Apple Orchard.” J. Appl. Entomol. 114: 473-478.

[21] Liang, W., and Huang, M. 1994. "Influence of Citrus 
546 A Mechanism for Biological Control-Tempo-Spatial Synchronization of Natural Enemy and Insect Pest Population Dynamics at the Peak by Increase of Biodiversity

Orchard Ground Cover Plant on Arthropod Communities in China: A Review." Agri. Ecosys. Environ. 50: 29-37.

[22] Li, X. Y., Chen, A. D., and Zhao, X. Q. 2006. "Effects of Vegetation Diversity on the Occurrence Period and Species Dynamics of Insets.” SW Chin. J. Agric. Sci. 19 (3): 519-524.

[23] Russell, E. P. 1989. "Enemies Hypothesis: A Review of the Effect of Vegetational Diversity on Predatory Insects and Parasitoids." Environ. Entomol. 18: 590-599.

[24] Blasius, B., and Stone, L. 2000. "Non-linearly and the Moran Effect." Nature 406 (24): 846-847.

[25] Moran, P. A. P. 1953. "The Statistical Analysis of the
Canadian Lynx Cycle.” Austl. J. Zool. 1: 291-298.

[26] Royama, T. 1992. Analytical Population Dynamics. London: Champman \& Hall Press.

[27] Korpimaki, E., and Krebs, C. J. 1996. "Predation and Population Cycles of Small Mammals: A Reassessment of the Predation Hypothesis." Biosciences 46: 754-764.

[28] Post, E., and Forchhammer, M. C. 2002. "Synchronization of Animal Population Dynamics by Large-Scale Climate.” Nature 420: 168-171.

[29] Cattadori, I. M., Haydon, D. T., Hudson, P. J. 2005. "Parasites and Climate Synchronize Red Grouse Populations." Nature 433: 737-741. 